\title{
INFLUÊNCIA DO NITROGÊNIO E DAS LÂMINAS DE IRRIGAÇÃO NA QUALIDADE FISIOLÓGICA DAS SEMENTES DE MAMOEIRO ${ }^{1}$
}

\author{
ROBSON CELESTINO MEIRELES²; ROBERTO FERREIRA DA SILVA33; EDUARDO FONTES ARAUJO4; \\ LUCILÉA SILVA DOS REIS ${ }^{5}$; GUILHERME BASTOS LYRA ${ }^{6}$; ALBANISE BARBOSA MARINHO ${ }^{6}$.
}

\begin{abstract}
RESUMO - O presente trabalho teve por objetivo verificar a qualidade fisiológica das sementes de mamoeiro em função da aplicação de diferentes níveis de nitrogênio e lâminas de irrigação. Para a implantação do cultivo foram utilizadas plantas de mamoeiro da cultivar Golden (grupo Solo), dispostas em fileiras duplas e simples, totalizando a área de 5,04m2 por planta e $120,96 \mathrm{~m} 2$ por parcela. Os tratamentos foram constituídos por cinco lâminas de irrigação equivalentes a 70, 90, 110, 130 e $150 \%$ da evapotranspiração de referência, estimada pela equação de Penman-Monteith (FAO56) e quatro doses de nitrogênio $(10,20,30 \mathrm{e} 40 \mathrm{~g} /$ planta) disponibilizadas mensalmente até o término do experimento, sendo utilizado o sulfato de amônio como fonte desse nutriente. As sementes foram extraídas de frutos hermafroditas e lavadas em peneira de metal para a remoção da sarcotesta. As características avaliadas foram germinação e vigor, estimadas pelos testes de germinação, primeira contagem de germinação, classificação de plântulas e peso da matéria seca da plântula. O delineamento estatístico utilizado foi o inteiramente casualizado no esquema fatorial, sendo os dados submetidos à análise de variância e regressão. Com os resultados obtidos foi possível concluir que a dose de $10 \mathrm{~g}$ de nitrogênio associada à lâmina de irrigação correspondente a 109\% da evapotranspiração, resultou em maiores valores de germinação e que doses de nitrogênio, associada a lâmina adequada de irrigação, contribuíram de maneira significativa para o aumento do vigor das sementes de mamoeiro.
\end{abstract}

Termos para indexação: nutriente, germinação, vigor.

\section{THE INFLUENCE OF NITROGEN AND IRRIGATION LEVELS ON THE PHYSIOLOGICAL QUALITY OF PAPAYA SEEDS.}

\begin{abstract}
The objective of this study was to verify the physiologic quality of papaya tree seeds, in function of different levels of nitrogen application and irrigation levels. Papaya tree plants of the Golden cultivar (Solo group) were used set in double and single rows, in a total area of $5.04 \mathrm{~m}^{2}$ per plant and $120.96 \mathrm{~m}^{2}$ per plot. Treatments were consisted of five irrigation levels, equivalent to 70 , $90,110,130$ and $150 \%$ of the reference evapotranspiration, estimated by the Penman- Monteith (FAO-56) equation and four doses of nitrogen $(10,20,30$ and 40g/plant), provided monthly until the end of the experiment, with ammonia sulfate as source of this nutrient. Seeds were extracted
\end{abstract}

\footnotetext{
${ }^{1}$ Submetido em 19/11/2007. Aceito para publicação em 03/06/2008. Parte de tese de doutorado em Produção Vegetal na Universidade Estadual do Norte Fluminense Darcy Ribeiro.

${ }^{2}$ Doutorando em Produção Vegetal - UENF - Campos dos Goytacazes, RJ. robmeireles@hotmail.com
}

${ }^{3}$ Eng. Agr. Dr. Professor Titular - UENF - Campos dos Goytacazes, RJ. roberto@uenf.br
${ }^{4}$ Eng. Agr. Dr. Professor Departamento de Fitotecnia - UFV, efaraujo@ ufv.br

${ }^{5}$ Doutoranda em Genética e Melhoramento de Plantas-UENF, lucileasreis@ yahoo.com.br

${ }^{6}$ Doutor (a) em Produção Vegetal - UENF - Campos dos Goytacazes, RJ. 
from hermaphrodite fruits and washed in a metal sieve to remove the sarcotesta. The assessed characteristics were germination and vigor, estimated by germination tests, germination first count, seedling classification and weight of seedling dry matter. A completely randomized design with treatments in a factorial scheme was used. Data were submitted to variance and regression analyses. From the obtained results, it was concluded that the $10 \mathrm{~g}$ dose of nitrogen associated to an irrigation level that corresponded to $109 \%$ evapotranspiration resulted in greater germination values; and that the nitrogen doses, associated to suitable irrigation levels, contributed significantly to the increase in papaya tree seed vigor.

Indexs terms: nutrient, germination, vigor.

\section{INTRODUÇÃO}

A qualidade de sementes, para Popinigis (1985), é fator resultante da ação de diversas características, tais como viabilidade, vigor, teor de água, maturidade, danos mecânicos, infecção por patógenos, tamanho, longevidade, entre outros. Em complementação a este conceito, Carvalho e Nakagawa (2000) afirmaram que a qualidade de sementes é expressão da interação de componentes genéticos, fisiológicos, físicos e sanitários. Sendo assim, a qualidade final das sementes pode ser dependente do ambiente, não só de beneficiamento ou estocagem, mas principalmente do ambiente de estabelecimento do cultivo.

Para Sá (1994), os nutrientes apresentam papel relevante durante as fases de formação, desenvolvimento e maturação das sementes, principalmente na constituição das membranas e no acúmulo de lipídios, carboidratos e proteínas. Concomitantemente, é importante levar-se em consideração a disponibilidade hídrica adequada, bem como níveis nutricionais satisfatórios, para a boa formação das sementes e, conseqüentemente sua melhor qualidade. Ademais, a disponibilidade de níveis necessários de nutrientes contribui para que características como tamanho, forma, peso e coloração, além da ausência de anomalias decorrentes de deficiências minerais, sejam obtidas de maneira desejada (Delouche, 1981).

Dentre os nutrientes essenciais para o desenvolvimento da planta, o nitrogênio desempenha importantes funções, estando relacionado com a fixação de vagens e o enchimento das sementes. No entanto, a disponibilidade desse nutriente deve ser realizada de maneira criteriosa, pois sua deficiência ou excesso pode acarretar problemas de ordem química, visual, citológica, metabólica, e conseqüentemente, comprometer a frutificação e a produção de sementes (Malavolta, 1976).

Conde e Garcia (1988), estudando o efeito de cinco diferentes doses de nitrogênio sobre a germinação de sementes de capim-braquiária, verificaram que a aplicação de $150 \mathrm{Kg} / \mathrm{ha}$ de nitrogênio propiciou a melhor porcentagem de germinação, superando em mais de $184 \%$ a germinação das sementes das plantas que não receberam adubação nitrogenada. Nesse sentido, Calarota e Carvalho (1984), avaliando o efeito do nitrogênio na qualidade fisiológica das sementes de girassol, utilizaram cinco diferentes doses desse nutriente e verificaram que a aplicação de $7 \mathrm{~g}$ por planta, 50 dias após a semeadura, aumentou, de maneira significativa, os níveis de proteínas, bem como a germinação e o vigor das sementes.

Além de bons níveis nutricionais, a planta matriz necessita que a disponibilidade hídrica seja otimizada, uma vez que o vigor das sementes pode ser comprometido quando o desenvolvimento e o acúmulo de matéria seca sofrem alterações. Neste contexto, os níveis de água no solo devem ser estudados de forma mais detalhada, uma vez que a água é responsável pela translocação dos compostos formados durante o processo fotossintético para o interior da semente em formação. Além disso, as reações que metabolizam tais compostos e os transformam em reservas são altamente dependentes de água. Assim, é comum o elevado conteúdo dessa substância na semente durante a fase de desenvolvimento e acúmulo de matéria seca (Carvalho e Nakagawa, 2000).

Deste modo, objetivou-se com o trabalho verificar a qualidade fisiológica das sementes de mamoeiro em função da aplicação de diferentes níveis de nitrogênio e lâminas de irrigação.

\section{MATERIAL E MÉTODOS}

O experimento de campo foi instalado na Fazenda Santa Terezinha pertencente à Caliman Agrícola Ltda, localizada 
no município de Linhares - ES. As análises de laboratório foram conduzidas no Setor de Produção e Tecnologia de Sementes do Laboratório de Fitotecnia (LFIT) da Universidade Estadual do Norte Fluminense Darcy Ribeiro (UENF) em Campos dos Goytacazes - RJ.

Para a implantação do cultivo foram utilizadas plantas de mamoeiro da cultivar Golden (grupo Solo), dispostas em fileiras duplas e simples, sendo a distância empregada entre as fileiras de $3,6 \mathrm{~m}$ e $2 \mathrm{~m}$, respectivamente, e o espaçamento entre as plantas dentro das fileiras de $1,80 \mathrm{~m}$, totalizando $5,04 \mathrm{~m}^{2}$ por planta e $120,96 \mathrm{~m}^{2}$ por parcela.

Os tratamentos foram constituídos por cinco lâminas de irrigação equivalentes a 70,90,110, 130 e $150 \%$ da evapotranspiração de referência, estimada pela equação de Penman-Monteith (FAO-56) e quatro doses de nitrogênio (10, 20, 30 e 40g/planta) disponibilizadas mensalmente até o término do experimento, sendo utilizado o sulfato de amônio como fonte desse nutriente.

As sementes foram provenientes de frutos hermafroditas colhidos no estádio dois de maturação e mantidos em repouso por oito dias em condição ambiente. As sementes foram extraídas manualmente e lavadas em peneira de metal para a remoção da sarcotesta.

As características avaliadas foram germinação e vigor, estimadas pelos testes de germinação, primeira contagem de germinação, classificação de plântulas e peso da matéria seca da plântula.

Teste de germinação - utilizando como substrato o papel germitest, umedecido com água destilada na proporção de 2,5 vezes o peso do papel seco, foram utilizadas quatro subamostras com 50 sementes por repetição, as quais foram mantidas em germinador do tipo BOD com temperatura alternada de $20-30^{\circ} \mathrm{C}$ ( $16 \mathrm{~h}$ de escuro e $8 \mathrm{~h}$ de luz) por 30 dias. Após este período, foi realizada a avaliação das plântulas normais conforme prescrito nas Regras para Análise de Sementes (RAS), sendo os resultados expressos em porcentagem de plântulas normais (Brasil, 1992).

Primeira contagem de germinação - Executada em conjunto ao teste de germinação, sendo considerada como germinada, a semente com protrusão da raiz primária no $15^{\circ}$ dia após a instalação do teste. $\mathrm{O}$ vigor foi expresso pela porcentagem das sementes que emitiram a radícula.

Classificação do vigor de plântulas - As plântulas normais foram avaliadas de acordo com o seu vigor, sendo classificadas como plântulas normais fortes, quando, além de apresentarem todas as estruturas essenciais, destacavamse das demais por seu maior tamanho e vigor da raiz e da parte aérea (aproximadamente $5 \mathrm{~cm}$ ). Os resultados foram expressos em porcentagem de plântulas normais fortes (Martins et al., 2005).

Peso da matéria seca da plântula - empregou-se como substrato o papel germitest, umedecido com água destilada na proporção de 2,5 vezes o peso do papel seco, tendo sido utilizadas quatro repetições de 10 sementes, as quais foram mantidas em germinador do tipo BOD com temperatura alternada de $20-30^{\circ} \mathrm{C}$ ( $16 \mathrm{~h}$ de escuro e $8 \mathrm{~h}$ de luz) por 30 dias. Após este período as plântulas de cada tratamento e respectivas repetições, foram acondicionadas em sacos de papel e postas para secar em estufa de circulação de ar a $72^{\circ} \mathrm{C}$, durante 72 horas. Transcorrido este tempo, as plântulas foram dispostas em um dessecador e, depois de resfriadas, foram pesadas em balança de precisão, obtendo-se o peso total que foi dividido pelo número de plântulas, sendo os resultados expressos em mg/plântula (Nakagawa, 1999).

O delineamento estatístico utilizado foi o inteiramente casualizado no esquema fatorial 5 x 4 (cinco lâminas de irrigação e quatro doses de nitrogênio). Os dados foram submetidos à análise de variância e regressão linear ou quadrática, de modo que o modelo escolhido foi aquele que melhor se ajustou aos dados obtidos.

\section{RESULTADOS E DISCUSSÃO}

Na Figura 1 é possível observar que a aplicação de nitrogênio, na dose de $10 \mathrm{~g}$, proporcionou o melhor resultado de vigor, avaliado pela primeira contagem do teste de germinação. No entanto, esse resultado somente foi obtido quando a referida dose foi associada à lâmina de irrigação correspondente a 150\% da evapotranspiração de referência.

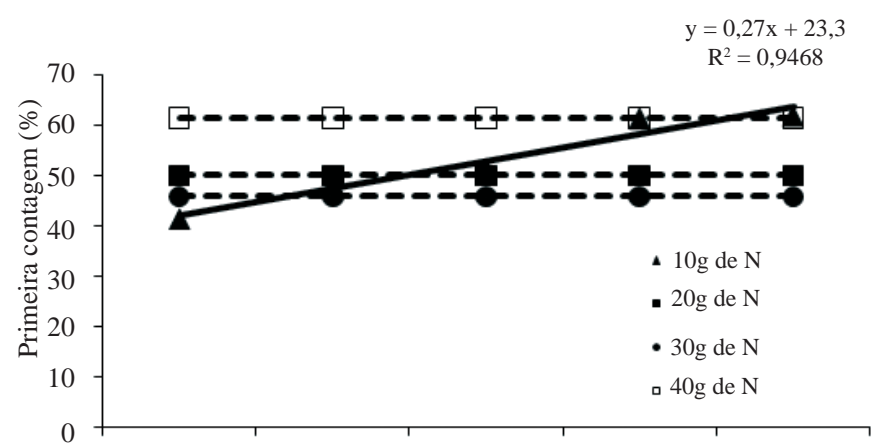

FIGURA 1. Vigor de sementes de mamoeiro pelo teste de primeira contagem de germinação, em função de cinco lâminas de irrigação e quatro doses de nitrogênio. 
Deste modo, verificou-se que, na medida em que a lâmina de irrigação disponibilizada para a cultura decresceu, ocorreu decréscimo linear na porcentagem de vigor das sementes. Independente da lâmina de irrigação aplicada, elevado vigor das sementes também foi observado quando se utilizou a dose de $40 \mathrm{~g}$ de $\mathrm{N}$.

De maneira análoga aos dados de primeira contagem, a aplicação de $10 \mathrm{~g}$ de $\mathrm{N}$ também proporcionou o melhor resultado para a germinação, conforme mostra a Figura 2. $\mathrm{Na}$ mesma figura observa-se que os maiores valores para germinação foram encontrados quando foi a aplicada lâmina de irrigação correspondente a 109\% da evapotranspiração, valor esse obtido matematicamente pelo ponto de máximo da equação de regressão. Assim, verificou-se a possibilidade de produção de sementes de mamoeiro de alta qualidade, sem a necessidade do uso dispendioso de adubação nitrogenada, uma vez que esta dose se tornou mais eficiente quando associada com determinadas lâminas de irrigação.

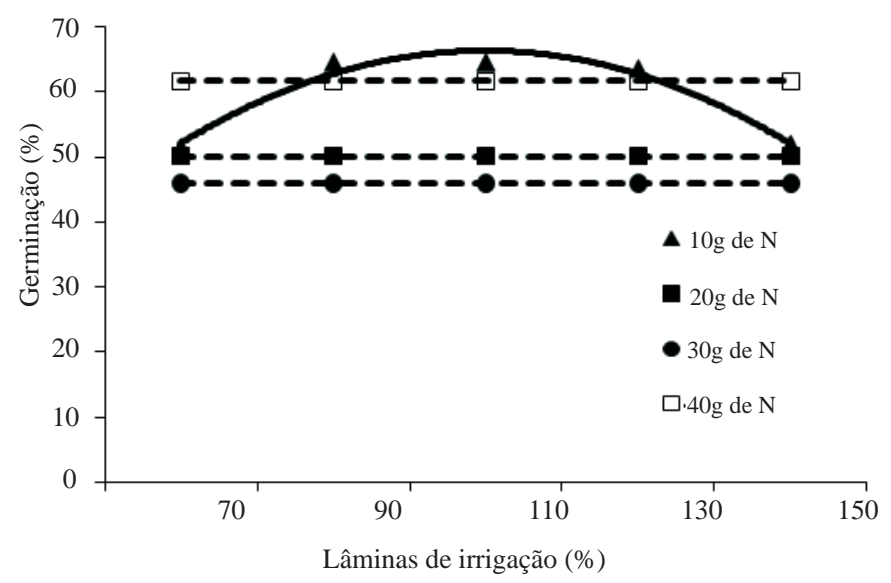

FIGURA 2. Germinação de sementes de mamoeiro, em função de cinco lâminas de irrigação e quatro doses de nitrogênio

Nesse sentido, Oliveira et al. (2001) trabalhando com plantas de feijão caupi, observaram que a aplicação da adubação nitrogenada no solo, na dose de $55 \mathrm{~kg} / \mathrm{ha}$, proporcionou maior produção e maior poder germinativo para as sementes, evidenciando ser esta a adubação nitrogenada mais adequada a ser utilizada nos campos de produção de sementes para essa cultura. Esses mesmos resultados também foram observados por Soratto et al. (1999) que verificaram aumento linear no poder germinativo das sementes de feijão comum e maior expressão do vigor, quando se aplicou nitrogênio no solo.

Os resultados do teste de classificação de plântulas, verificados na Figura 3, mostram que a dose de $40 \mathrm{~g}$ de nitrogênio propiciou maior porcentagem de vigor quando associada à lâmina de irrigação correspondente a $70 \%$ da evapotranspiração de referência da cultura, comparandose com as menores doses desse nutriente. Para essa mesma dose, é possível observar a ocorrência de decréscimo linear na porcentagem de vigor à medida que se aumentou a disponibilidade de água para as plantas.

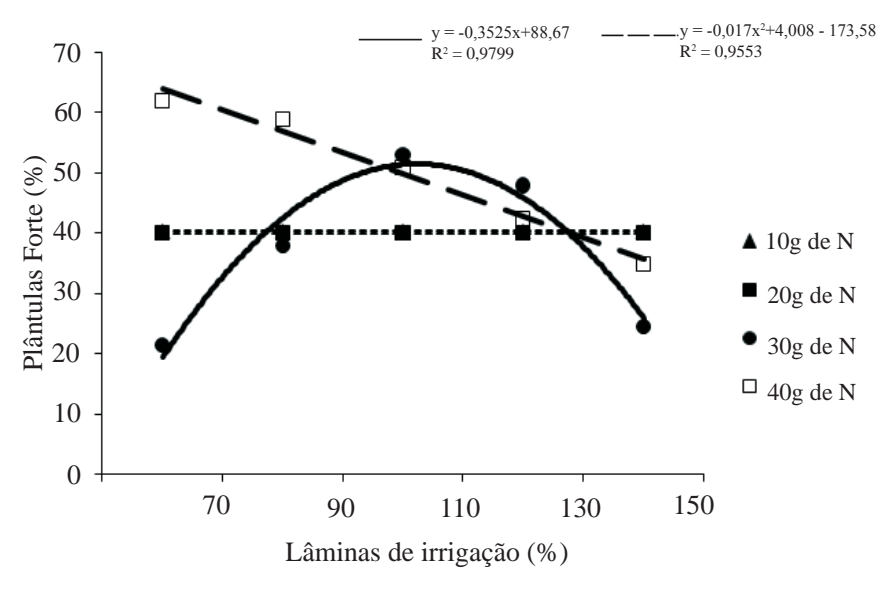

FIGURA 3. Vigor de sementes de mamoeiro, pelo teste de classificação de plântulas, em função de cinco lâminas de irrigação e quatro doses de nitrogênio.

Tais resultados corroboram com Oliveira et al. (2003) que, avaliando o efeito da adubação nitrogenada sobre o vigor das sementes de feijoeiro, utilizando cinco doses desse nutriente, verificaram o aumento linear da emergência no campo, em função da aplicação de nitrato de cálcio, à medida que se disponibilizou mais nitrogênio para a cultura, uma vez que a emergência máxima de $70 \%$ foi obtida na dose correspondente a $100 \mathrm{~kg} \cdot \mathrm{ha}^{-1}$ de nitrogênio.

$\mathrm{Na}$ figura 4, observa-se que a dose de $10 \mathrm{~g}$ de nitrogênio associada à lâmina de irrigação, correspondente a $70 \%$ resultou nos maiores valores para matéria seca de plântula, entretanto, com o aumento das lâminas de irrigação, houve decréscimo no peso de matéria seca. 


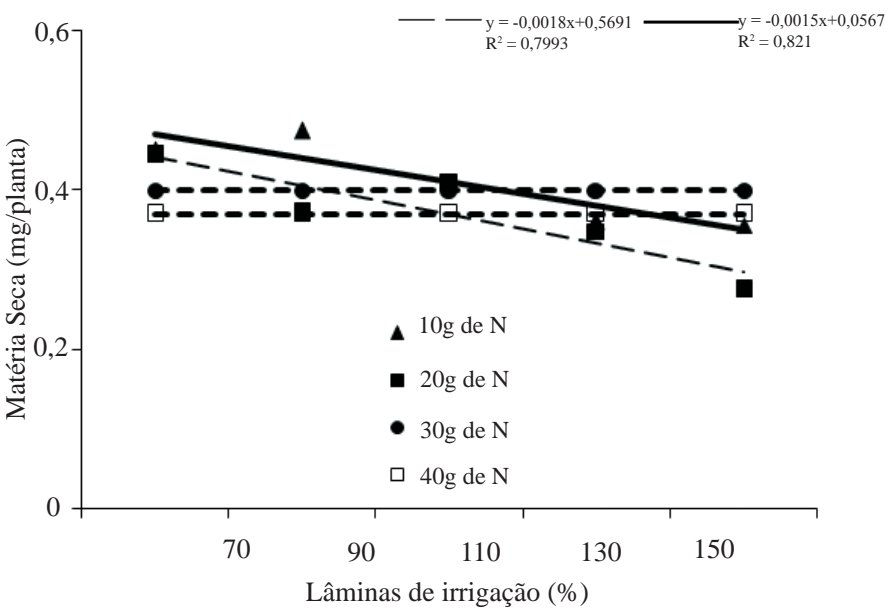

FIGURA 4. Vigor, estimado pela determinação da massa de matéria seca da plântula, em função de cinco lâminas de irrigação e quatro doses de nitrogênio.

De acordo com os resultados obtidos neste estudo, observa-se que a produção de sementes com elevado vigor é possível, utilizando-se doses reduzidas de nitrogênio associadas com menores lâminas de irrigação, caracterizando menores investimentos na implantação e condução das lavouras de mamoeiro e, conseqüentemente, gerar maior lucratividade para o produtor.

\section{CONCLUSÕES}

- A dose de $10 \mathrm{~g}$ de nitrogênio associada à lâmina de irrigação correspondente a 109\% da evapotranspiração favorece a germinação de sementes de mamoeiro;

- Doses de nitrogênio, associadas a lâminas adequadas de irrigação, contribuem de maneira significativa para o aumento do vigor das sementes de mamoeiro.

\section{REFERÊNCIAS}

BRASIL. Ministério da Agricultura e Reforma Agrária. Secretaria Nacional de Defesa Sanitária. Departamento Nacional de Defesa Vegetal. Coordenação de Laboratório vegetal. Regras para análise de sementes. Brasília, DF: SNDA/DNDV/CLAV, 1992, 365p.
CALAROTA, N. E. E CARVALHO, N. M. Efeitos da adubação nitrogenada em cobertura sobre os conteúdos de óleo e de proteína e a qualidade fisiológica de sementes de girassol (Helianthus annus). Revista Brasileira de Sementes, v.6, n.3, p.41-50, 1984.

CARVALHO, N.M.; NAKAGAWA, J. Sementes: ciência, tecnologia e produção. Campinas: Fundação Cargil. 2000. 588p.

CONDE, A.R.; GARCIA, J. Efeito de níveis e épocas de aplicação de nitrogênio na produção e qualidade das sementes de capim-colonião. Revista Brasileira de Sementes, v.10, n.1, p.33-42, 1988.

DELOUCHE, J.C. Metodología de pesquisa em sementes. III. Vigor, envigoramento e desempenho no campo. Revista Brasileira de Sementes, v.3, n.2, p.57-64, 1981.

MALAVOLTA, F. Manual de química agrícola: nutrição de plantas e fertilidade do solo. São Paulo: Agronômica Ceres, 1976, 528p.

MARTINS, G.N.; SILVA, R.F.; ARAÚJO, E.F.; PEREIRA, M.G.; VIEIRA, H.D.; VIANA, A.P. Influência do tipo de fruto, peso específico das sementes e período de armazenamento na qualidade fisiológica de sementes de mamão do grupo formosa. Revista Brasileira de Sementes. v. 27, n.2, p. $12-17,2005$.

NAKAGAWA, J. Testes de vigor baseados no desempenho das plântulas. In: KRZYZANOWSKI, F.C.; VIEIRA, R.D.; FRANÇA NETO, J.B. (Ed.) Vigor de sementes: conceitos e testes. Londrina: ABRATES, 1999. p.2-13.

OLIVEIRA, A.P.;.; BRUNO, G.B.; ALVES, E.U.; PEREIRA, E.L. Produção e qualidade de sementes de feijãocaupi (Vigna unguiculata L. Walp), em função de doses e formas de aplicação de nitrogênio. Revista Brasileira de Sementes, v. 23, n. 2, p.215-221, 2001.

OLIVEIRA, A. P.; PEREIRA, E. L., BRUNO, R.L.A, ALVES, E.U., COSTA, R. F; LEAL, F.R. Produção e qualidade fisiológica de sementes de feijão-vagem em função de fontes e doses de nitrogênio. Revista Brasileira de Sementes, v. 25, n 1, p.49-55, 2003.

POPINIGIS, F. Fisiologia da semente. 2. ed. Brasília, DF: AGIPLAN, 1985. 289p.

SÁ, M.E. Importância da adubação na qualidade de semente. In: SÁ, M.E.; BUZZETI, S. (Ed.). Importância da adubação na qualidade dos produtos agrícolas. São Paulo: Ícone, 1994. p.65-98.

SORATTO, R.P.; BENETOLI, S.; CHIDI, S.N.; ART, O.; SÁ, M.E. Resposta do feijoeiro (Phaseolus vulgaris L.) à 
aplicação de nitrogênio em cobertura e molibdênio via foliar.

II - Qualidade fisiológica das sementes. In: REUNIÃO
NACIONAL DE PESQUISA DE FEIJÃO, 6., 1999, Salvador. Anais. Salvador: EMBRAPA-CNPFA, 1999. p.595-598. 